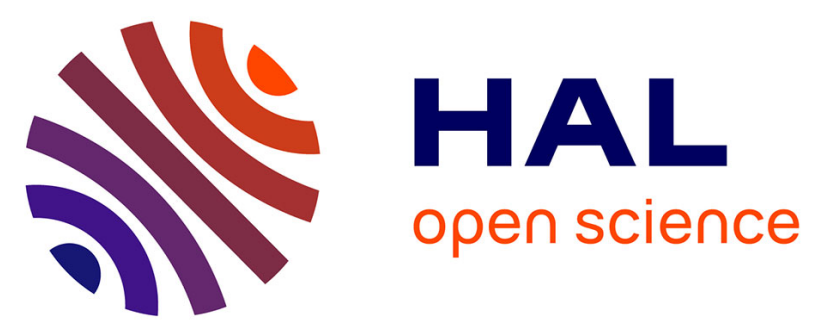

\title{
Edema of the optic tract in patients with tumors of the sellar region clinical and visual implications in the pediatric population
}

Aurore Bussat, Maia Proisy, Bertrand Bruneau, Guillaume Bouzillé, Céline Chappé, Laurent Riffaud

\section{To cite this version:}

Aurore Bussat, Maia Proisy, Bertrand Bruneau, Guillaume Bouzillé, Céline Chappé, et al.. Edema of the optic tract in patients with tumors of the sellar region clinical and visual implications in the pediatric population. Journal of Neurosurgery. Pediatrics, 2018, 21 (5), pp.516-522. 10.3171/2017.11.PEDS17526 . hal-01807365

\section{HAL Id: hal-01807365}

\section{https://hal-univ-rennes1.archives-ouvertes.fr/hal-01807365}

Submitted on 19 Jun 2018

HAL is a multi-disciplinary open access archive for the deposit and dissemination of scientific research documents, whether they are published or not. The documents may come from teaching and research institutions in France or abroad, or from public or private research centers.
L'archive ouverte pluridisciplinaire HAL, est destinée au dépôt et à la diffusion de documents scientifiques de niveau recherche, publiés ou non, émanant des établissements d'enseignement et de recherche français ou étrangers, des laboratoires publics ou privés. 


\title{
Edema of the optic tract in patients with tumors of the sellar region: clinical and visual implications in the pediatric population
}

\author{
Aurore Bussat, MD, ${ }^{1}$ Maia Proisy, MD, ${ }^{2}$ Bertrand Bruneau, MD, ${ }^{2}$ Guillaume Bouzillé, MD, ${ }^{3,4}$ \\ Céline Chappé, MD, ${ }^{5}$ and Laurent Riffaud, MD, $\mathrm{PhD}^{4,6}$
}

Departments of ${ }^{1}$ Ophthalmology, ${ }^{2}$ Pediatric Radiology, ${ }^{5}$ Pediatric Oncology, and ${ }^{6}$ Neurosurgery and ${ }^{3} \mathrm{Clinical}$ Data Center, Rennes University Hospital, Rennes; and ${ }^{4}$ Inserm U1099 LTSI, University of Rennes 1, Rennes, France

\begin{abstract}
OBJECTIVE Tumor-related edema of the optic tract (EOT) corresponds to a preferential posterior distribution of peritumoral edema along the white matter tract of the visual system. To date, the consequences of EOT have never been evaluated specifically in the pediatric population. In this study, the authors attempted to identify clinical and radiological features associated with the development of EOT and the specific influence of this edema on visual function.
\end{abstract}

METHODS A retrospective review was performed of data collected from patients younger than 18 years who underwent surgery for a tumor in the sellar region at the authors' institution between January 2005 and January 2016. Data were collected on patient characteristics, ophthalmological evaluations, and neuroimaging findings. To evaluate and compare visual function impairment, ophthalmological data were converted to a global visual function score, which took into account visual acuity, visual field evaluations, and laterality deficiencies. The visual acuity score was defined according to the International Classification of Diseases, 10th Revision. Visual field deficiencies were converted to a score of 0-2. Two opposing groups were then distinguished according to the presence or absence of EOT. Visual acuity, visual field results, and global scores were compared between groups before and after treatment.

RESULTS Twenty-six patients were included in the study: 17 patients with craniopharyngioma, 3 patients with pilocytic astrocytoma, 2 patients with ganglioglioma, 2 patients with germ cell tumor, 1 patient with macroprolactinoma, and 1 patient with Rathke's cleft cyst. There were 11 children in the group with edema and 15 children in the group without edema. None of the following criteria were statistically different between the 2 groups: age, sex, clinical symptoms at presentation (endocrine deficiency or intracranial hypertension signs), incidence of hydrocephalus, compression of the optic tracts and mass effect on the optic chiasm, tumor size and localization, presence of intratumoral cysts, treatment, type of tumor, or recurrence. The median global visual function and visual acuity scores were not significantly different between the groups either at presentation or at final evaluation. The visual field score was lower (i.e., more deficiency) in the group with edema than in the group without edema $(p<0.05) ; 89 \%$ of the patients with edema had severe or mild visual field impairment versus only $40 \%$ of the patients without edema. At the final examination after treatment, the visual field scores were not different between the 2 groups. Although not significant, the number of patients with optic disc pallor was greater in the group without edema both at diagnosis and at final examination.

CONCLUSIONS This study confirms that EOT in the context of sellar region tumor in children is not necessarily associated with a less-favorable visual prognosis.

https://thejns.org/doi/abs/10.3171/2017.11.PEDS17526

KEY WORDS optic tracts; edema; sellar region; brain tumor; pediatric; MRI; surgical technique

$\mathrm{T}$ UMOR-RELATED edema of the optic tract (EOT) was first described in 1990 in association with adult craniopharyngioma as a hyperintense signal on T2-weighted magnetic resonance (MR) images along the optic tracts that produced a particular radiological sign, i.e., the "moustache sign."5 This corresponds to a preferen- tial posterior distribution of peritumoral edema along the white matter tract of the visual system. ${ }^{3,19}$ This edema was first considered to be specific to craniopharyngioma, ${ }^{6,11}$ but it has since been described in other types of tumors and almost exclusively in adults.

Few studies have assessed the clinical significance of 
EOT in parasellar tumors. Some reports have found this edema to be correlated with visual impairment, ${ }^{3,12,13,21}$ but others have not confirmed this negative influence..$^{11,15}$ To date, the consequence of EOT has never been evaluated specifically in the pediatric population. Here, we discuss a series of 26 children who presented with a tumor of the sellar region to analyze both distinctive clinical and radiological features associated with the development of EOT and the specific influence of this edema on visual function. The aim of the study was to clarify whether the presence of such an edema represents a factor of visual impairment in tumors of the sellar region, which could influence our routine practice and treatment strategies.

\section{Methods}

We retrospectively reviewed collected data from patients younger than 18 years who were underwent surgery for a tumor of the sellar region at our institution between January 2005 and January 2016. Data were collected on patient characteristics, ophthalmological evaluations, and neuroimaging findings. The surgeries were performed by a senior pediatric neurosurgeon (L.R.), and tumor type was confirmed by histological analysis in all cases. Surgical strategies were tailored to each patient: biopsy when a malignant tumor was suspected, or as complete a resection of the tumor as possible in the other cases, which was guided by what the surgeon considered prudent at the time.

The patients with intrasellar tumors that were located a distance from the visual pathways were excluded: microadenoma, intrasellar Rathke's cleft cyst, inflammation or infectious lesion of the pituitary gland, and orbital tumor. Primary optic nerve and chiasm tumors, such as optic nerve gliomas, were excluded because they represent intrinsic tumors of the optic pathways and edema could not be differentiated from local tumoral infiltration. Cases of neurofibromatosis type 1 were also excluded because of the presence of unidentified bright objects in the basal ganglia of patients with this disorder, which could generate false positives.

\section{Patient Characteristics}

Of 49 children who were initially identified, 23 were excluded: 2 patients died soon after surgery, 8 patients had optic nerve glioma, 1 patient had ganglioglioma and early and profound loss of vision, 7 patients had microadenoma, 1 patient had nonspecific pituitary inflammation, 1 patient had pituitary abscess, 2 patients had intrasellar Rathke's cleft cyst, and 1 patient did not have an initial MR image available. Finally, 26 patients comprised our patient cohort.

Two opposing groups were then defined according to the presence or absence of EOT on MR images.

Symptoms at presentation were analyzed and compared between groups: presence or absence of the signs of intracranial hypertension and the signs of endocrine deficiency and hypothalamic syndrome. The type of surgical procedure (total or partial resection or biopsy), adjuvant treatment (chemotherapy or radiotherapy), and presence or absence of recurrence were also examined. None of the patients were treated with glucocorticosteroids because their use is not a routine therapeutic strategy for tumors of
TABLE 1. Global visual function score*

\begin{tabular}{|c|c|}
\hline \multicolumn{2}{|c|}{ Visual acuity score $†$} \\
\hline 0 & $\begin{array}{l}\text { Severe to total vision loss: no light perception to } \\
\text { BCVA } \leq 0.1\end{array}$ \\
\hline 1 & Moderate vision loss: $B C V A \geq 0.12$ to $<0.3$ \\
\hline 2 & Mild vision loss: $B C V A \geq 0.3$ to $\leq 0.7$ \\
\hline 3 & Normal vision: $B C V A \geq 0.8$ \\
\hline \multicolumn{2}{|c|}{ Visual field score } \\
\hline 0 & $\begin{array}{l}\text { Severe visual field deficiency: total loss of the } \\
\text { visual field of } 1 \text { eye, homonymous lateral } \\
\text { hemianopia, bitemporal hemianopia, \& hemi- } \\
\text { anopia plus any deficiency in the other eye }\end{array}$ \\
\hline 1 & $\begin{array}{l}\text { Mild to moderate visual field deficiency: diffuse } \\
\text { loss of sensibility, enlargement of the blind } \\
\text { spot, \& quadrantanopia in } 1 \text { or both eyes }\end{array}$ \\
\hline 2 & Normal \\
\hline \multicolumn{2}{|c|}{ Laterality } \\
\hline 0 & Both eyes involved \\
\hline 1 & 1 eye involved \\
\hline 2 & Normal \\
\hline
\end{tabular}

* The global visual function score consists of the sum of total visual acuity score in both eyes, visual field score, and laterality score (range 0-10).

$\dagger$ The total visual acuity is scored in both eyes (range $0-6$ ).

the sellar region at our institution, regardless of the radiological and ophthalmological conditions.

\section{Ophthalmological Examination}

Ophthalmological examinations were conducted by senior ophthalmologists either before or after treatment of the tumor. Practitioners were not aware of the presence or absence of EOT; this aspect was later studied retrospectively.

Best-corrected visual acuity (BCVA) for both eyes was evaluated before treatment, 3-6 months after treatment, and at the last follow-up (1-6 years later). Visual acuity was measured by using a Monoyer chart, Snellen chart, or Pigassou symbols chart that had been converted to decimals. Only distant vision was taken into account. Visual field deficiencies were described according to the side and type of deficit (hemianopia, quadrantanopia, diffuse loss of sensibility, enlarged blind spot, or normal). Data were collected separately for each eye and were graded into 3 groups (see the paragraph below about visual field deficiencies). The presence or absence of papilledema and optic disc pallor detected by fundus examination was also recorded. No patient had previously known strabismus or amblyopia.

To evaluate and compare visual function impairment, we converted ophthalmological data to a global visual function score (Table 1). This score ranged from 10 (normal visual acuity and visual field in both eyes) to 0 (both eyes had severe to total vision loss and severe visual field impairment). The global visual function score took into account asymmetrical visual deficiency in terms of visual loss (interocular difference in $\mathrm{BCVA} \geq 0.1$ ) and any visual field deficiency as follows: 0 , both eyes involved; 1 , one eye; 2 , neither. 

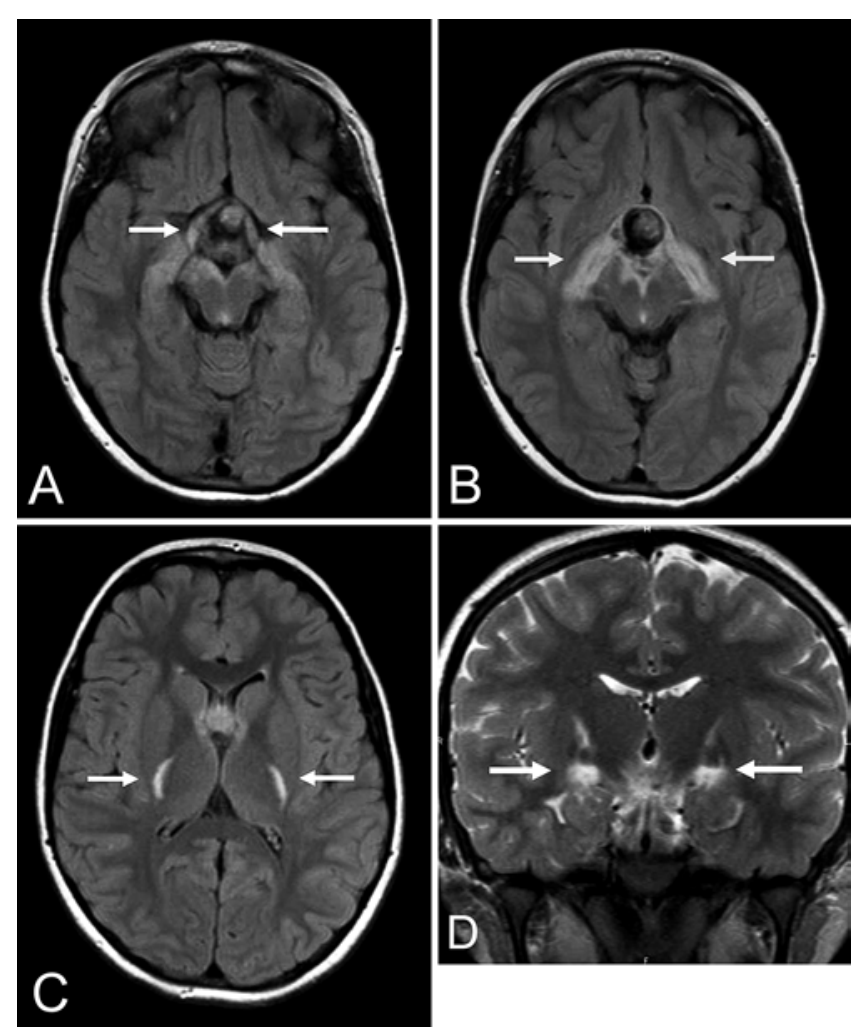

FIG. 1. Case 1. A 10-year-old girl with a germ cell tumor at diagnosis. A-C: Axial FLAIR MR images showing a bilateral hyperintense signal along the optic tracts (arrows) that produces the moustache sign.

D: Coronal T2-weighted MR image showing a symmetric hyperintense signal of the optic tracts (arrows).

The visual acuity score was defined according to the International Classification of Diseases, 10th Revision (code H54; http://apps.who.int/classifications/apps/icd/ icd10online2003/fr-icd.htm?gh53.htm+): ${ }^{21} 0$, severe to total vision loss (no light perception to BCVA $\leq 0.1$ ); 1 , moderate vision loss (BCVA $\geq 0.12$ to $<0.3$ ); 2 , mild vision loss ( $\mathrm{BCVA} \geq 0.3$ to $\leq 0.7$ ); 3 , normal vision $(\mathrm{BCVA} \geq 0.8$ ).

All visual fields were monocular, either automated or manual, and visual field deficiencies were converted into the following scores: 0 , severe visual impairment, including the total loss of the visual field of 1 eye, homonymous lateral hemianopia, bitemporal hemianopia, or hemianopia plus any deficiency in the other eye; 1 , mild visual impairment, including diffuse loss of sensibility, enlargement of the blind spot, and quadrantanopia in 1 or both eyes; and 2 , no visual field deficiency.

We compared visual acuity, visual field results, and global scores in both groups before and after treatment. Two patients in the edema group did not undergo initial visual acuity and visual field evaluations because of an emergency, and 5 patients in the group without edema were not given initial visual field evaluations because of their young age.

\section{Neuroimaging Findings}

All patients underwent pre- and postoperative MRI, including T1- and T2-weighted imaging. MR images were
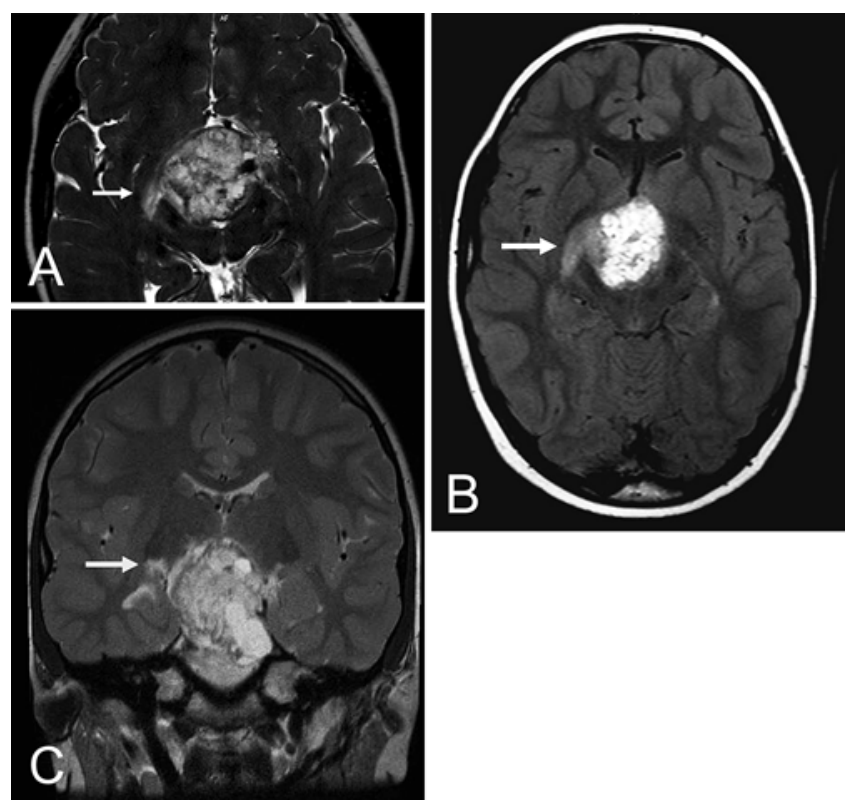

FIG. 2. Case 2. A 9-year-old boy with large retrochiasmatic craniopharyngioma at diagnosis. A: Axial T2-weighted MR image. The arrow indicates the optic tract. B: Axial FLAIR MR image. The arrow indicates the optic tract. C: Coronal T2-weighted MR image showing a hyperintense signal along the right optic tract (arrow).

reviewed by 2 pediatric radiologists (M.P. and B.B.). EOT was defined by a high-intensity signal along the optic tract on the axial and/or coronal planes on T2-weighted imaging and without any enhancement on T1-weighted imaging after contrast injection (Figs. 1-3). If present, EOT was classified into 3 categories: symmetrical, right predominance, or left predominance. Intensity was classified as slight, mild, or severe. Additional imaging findings were evaluated: tumor size (3 dimensions), tumor location (sellar, suprasellar, or both), presence of tumor cyst and hydrocephalus, presence of dilated Virchow-Robin spaces, and compression of the optic tracts. Upward or forward displacement of the optic chiasm and the type of mass effect on this structure, i.e., at a distance from the lesion, close contact, stretched and laminated, or invaded, were also studied.

\section{Statistical Analysis}

The Mann-Whitney U-test, Fisher exact test, and Pearson chi-square test were used for statistical comparisons of the 2 groups using R statistical software (version 3.3.3), and $\mathrm{p}<0.05$ was considered to be statistically significant.

\section{Results}

\section{Patient Characteristics}

Twenty-six patients were included in the study: 17 patients with craniopharyngioma, 3 patients with pilocytic astrocytoma, 2 patients with ganglioglioma, 2 patients with germ cell tumor, 1 patient with macroprolactinoma, and 1 patient with Rathke's cleft cyst (Table 2). There were 11 children in the group with edema and 15 children in the group without edema. None of the following criteria were 


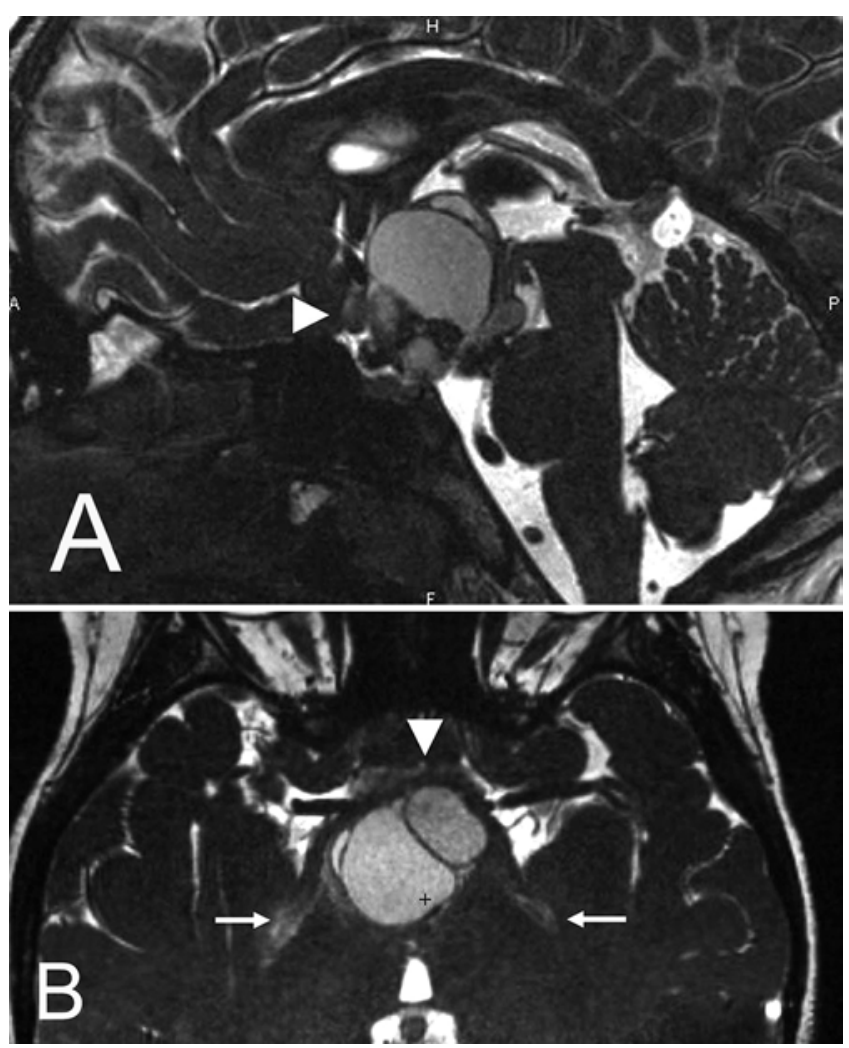

FIG. 3. Case 3. A 9-year-old girl with large cystic craniopharyngioma at diagnosis. A: Sagittal T2-weighted MR image showing forward displacement of the optic chiasm (arrowhead). B: Axial T2-weighted MR image showing a bilateral asymmetrical hyperintense signal along the optic tracts and predominantly on the right side (arrows). The arrowhead indicates the optic chiasm.

statistically different between the 2 groups: age, sex, clinical symptoms at presentation, treatment, type of tumor, recurrence.

\section{Ophthalmological Examination}

The results of the ophthalmological examinations of the 2 groups are presented in Table 3 .

The median global visual function scores were not statistically significantly different between the groups either at presentation or at final evaluation. Although nonsignificant, improvement of the median global visual function score was higher in the group without edema when compared with the group with edema (8.5 vs 7$)$. After treatment, the median global score in the group with edema improved in $56 \%$ of patients, remained stable in $11 \%$ of patients, and became worse in $33 \%$ of patients. In the second group, the median global score improved in $40 \%$ of patients, remained stable in $50 \%$ of patients, and became worse in $10 \%$ of patients.

For the visual acuity score, no statistical differences were observed between the 2 groups either at presentation or after treatment. The distributions of the degree of visual acuity deficiency and evolution of the scores before and after treatment were identical in the 2 groups.

Visual field score at presentation demonstrated some statistical differences between the 2 groups: the visual
TABLE 2. Patient characteristics and neuroimaging findings

\begin{tabular}{|c|c|c|c|}
\hline Characteristic & Group w/ Edema & $\begin{array}{l}\text { Group w/o } \\
\text { Edema }\end{array}$ & $\begin{array}{c}p \\
\text { Value }\end{array}$ \\
\hline No. of patients & 11 & 15 & \\
\hline Sex & & & $>0.99$ \\
\hline Male & $3(27)$ & $5(33)$ & \\
\hline Female & $8(73)$ & $10(67)$ & \\
\hline Age at presentation, yrs & $10(8-11.5)$ & $7(6-9.5)$ & 0.13 \\
\hline Intracranial hypertension & $5(45)$ & $9(60)$ & 0.46 \\
\hline $\begin{array}{l}\text { Signs of endocrine } \\
\text { deficiency }\end{array}$ & $5(45)$ & $9(60)$ & 0.46 \\
\hline $\begin{array}{l}\text { Type of endocrine } \\
\text { deficiency }\end{array}$ & & & 0.49 \\
\hline Diabetes insipidus & $1(9)$ & $2(13)$ & \\
\hline Growth retardation & $4(36)$ & $4(27)$ & \\
\hline Both & 0 & $3(20)$ & \\
\hline Hypothalamic syndrome & $4(36)$ & $4(27)$ & 0.68 \\
\hline $\begin{array}{l}\text { Compression of optic } \\
\text { tracts }\end{array}$ & $10(91)$ & $10(67)$ & 0.19 \\
\hline Position of optic chiasma & & & 0.18 \\
\hline Displaced upward & $6(55)$ & $3(20)$ & \\
\hline Displaced forward & 0 & $3(20)$ & \\
\hline $\begin{array}{l}\text { Mass effect on optic } \\
\text { chiasma }\end{array}$ & & & 0.48 \\
\hline At a distance & $1(9)$ & 0 & \\
\hline Close contact & $2(18)$ & $4(27)$ & \\
\hline Stretched & $5(45)$ & $4(27)$ & \\
\hline Invaded & $3(27)$ & $7(47)$ & \\
\hline \multicolumn{4}{|l|}{ Tumor size, mm } \\
\hline $\begin{array}{l}\text { Axial transverse } \\
\text { direction }\end{array}$ & $22.5(20.25-26.5)$ & $27(18.5-38.5)$ & 0.39 \\
\hline $\begin{array}{l}\text { Axial anteroposterior } \\
\text { direction }\end{array}$ & $22.5(20.25-27.75)$ & $25(17.5-39)$ & 0.56 \\
\hline Frontal height & $36(29.25-40)$ & $35(24-44.5)$ & 0.66 \\
\hline Localization & & & 0.37 \\
\hline Suprasellar & $2(18)$ & $1(7)$ & \\
\hline Supra- \& intrasellar & $6(55)$ & $11(73)$ & \\
\hline $\begin{array}{l}\text { Supra-, retro-, \& } \\
\text { intrasellar }\end{array}$ & 0 & $2(13)$ & \\
\hline 3rd ventricle & $1(9)$ & 0 & \\
\hline Other & $2(18)$ & $1(7)$ & \\
\hline $\begin{array}{l}\text { Dilated Virchow-Robin } \\
\text { spaces }\end{array}$ & $3(27)$ & $1(7)$ & 0.28 \\
\hline Intratumoral cysts & $9(82)$ & $15(100)$ & 0.17 \\
\hline Hydrocephalus & $3(27)$ & $5(33)$ & $>0.99$ \\
\hline Tumor type & & & 0.87 \\
\hline Craniopharyngioma & $6(55)$ & $11(73)$ & \\
\hline Pituitary adenoma & 0 & $1(7)$ & \\
\hline Pilocytic astrocytoma & $2(18)$ & $1(7)$ & \\
\hline Ganglioglioma & $1(9)$ & $1(7)$ & \\
\hline Germinoma & $1(9)$ & $1(7)$ & \\
\hline Rathke's cleft cyst & $1(9)$ & 0 & \\
\hline
\end{tabular}


» CONTINUED FROM PAGE 4

TABLE 2. Patient characteristics and neuroimaging findings

\begin{tabular}{lccr}
\hline \multicolumn{1}{c}{ Characteristic } & Group w/ Edema & $\begin{array}{c}\text { Group w/o } \\
\text { Edema }\end{array}$ & $\begin{array}{c}\mathrm{p} \\
\text { Value }\end{array}$ \\
\hline Surgery type & & & 0.23 \\
\hline Total resection & $4(36)$ & $4(27)$ & \\
\hline Partial resection & $4(36)$ & $10(67)$ & \\
\hline Biopsy & $3(27)$ & $1(7)$ & \\
\hline Radiotherapy & $2(18)$ & $2(13)$ & $>0.99$ \\
\hline Chemotherapy & $2(18)$ & $3(20)$ & $>0.99$ \\
\hline Recurrence & $6(55)$ & $6(40)$ & 0.69 \\
\hline
\end{tabular}

Values are reported as the number of patients (\%) or median (interquartile range).

field score was lower (i.e., more deficient) in the group with edema than in the group without edema $(\mathrm{p}<0.05)$; $89 \%$ of patients with edema had severe or mild visual field impairment versus only $40 \%$ of patients without edema. At the final examination following treatment, the visual field scores were no longer different between the 2 groups.

Although not significant, the number of patients with optic disc pallor was higher in the group without edema, both at diagnosis and at final examination. More than half of the patients in this group (57\%) exhibited optic disc pallor at fundus examination after treatment.

\section{Neuroimaging Data}

The neuroimaging findings are summarized in Table 2. Ten patients in each group had compression of the optic tracts, which represented $91 \%$ of the patients with edema and $67 \%$ of the patients without edema $(\mathrm{p}=0.19)$. All patients without edema but only 9 of $11(82 \%)$ patients in the group with edema had intratumoral cysts $(p=0.17)$. No statistical difference was observed between the 2 groups in terms of the mass effect on the optic chiasm or tumor size, regardless of which axis was measured, nor was the incidence of hydrocephalus at diagnosis different between the groups: approximately one-third of the patients had hydrocephalus in each group. Dilated Virchow-Robin spaces were rarely observed in either group.

Postoperative MRI demonstrated that EOT disappeared in all patients, except for 2 patients: a patient with a pilocytic astrocytoma still had EOT after biopsy, as did a second patient with ganglioglioma who underwent subtotal resection. In the latter case, edema disappeared after surgery and appeared again at recurrence.

\section{Discussion}

Although first described as craniopharyngioma, ${ }^{5}$ EOT was later reported in the adult population and in association with other types of tumors, such as pituitary metastasis, pituitary adenoma, meningioma, Rathke cleft's cyst, and germ cell tumor. ${ }^{2,13,16,18,20,21}$ No risk factor has yet been demonstrated. In a series of 49 adults and children who were treated for parasellar tumors, Hirunpat et al. ${ }^{6}$ found 7 EOTs exclusively in patients with craniopharyngioma and concluded that this type of edema shows good sensitivity
TABLE 3. Ophthalmological data

\begin{tabular}{|c|c|c|c|}
\hline Parameter & $\begin{array}{l}\text { Group w/ } \\
\text { Edema }\end{array}$ & $\begin{array}{c}\text { Group w/o } \\
\text { Edema }\end{array}$ & $\begin{array}{c}p \\
\text { Value }\end{array}$ \\
\hline No. of patients & 11 & 15 & \\
\hline \multicolumn{4}{|c|}{ Global vision function score } \\
\hline At presentation & $6(5-7)$ & $5.5(4.25-10)$ & 0.87 \\
\hline Final examination & $7(5.25-10)$ & $8.5(4-10)$ & 0.86 \\
\hline \multicolumn{4}{|c|}{ Visual acuity deficiency (1 eye) } \\
\hline At presentation & & & 0.75 \\
\hline Severe & $2(11)$ & $4(14)$ & \\
\hline Moderate & $3(17)$ & $3(11)$ & \\
\hline Mild & $1(5)$ & $5(18)$ & \\
\hline Normal & $12(67)$ & $16(57)$ & \\
\hline Final examination & & & 0.24 \\
\hline Severe & $2(9)$ & $5(17)$ & \\
\hline Moderate & $1(5)$ & $0(0)$ & \\
\hline Mild & $0(0)$ & $3(10)$ & \\
\hline Normal & $19(86)$ & $22(73)$ & \\
\hline \multicolumn{4}{|c|}{ Visual field deficiency (both eyes) } \\
\hline At presentation & & & $0.05^{*}$ \\
\hline Severe & $3(33)$ & $3(30)$ & \\
\hline Mild & $5(56)$ & $1(10)$ & \\
\hline Normal & $1(11)$ & $6(60)$ & \\
\hline Final examination & & & 0.99 \\
\hline Severe & $3(30)$ & $4(33)$ & \\
\hline Mild & $3(30)$ & $3(25)$ & \\
\hline Normal & $4(40)$ & $5(42)$ & \\
\hline \multicolumn{4}{|l|}{ Papilledema } \\
\hline At presentation & $1(10)$ & $1(8)$ & $>0.99$ \\
\hline Final examination & $0(0)$ & $0(0)$ & $>0.99$ \\
\hline \multicolumn{4}{|l|}{ Optic disc pallor } \\
\hline At presentation & $1(11)$ & $4(33)$ & 0.34 \\
\hline Final examination & $4(36)$ & $8(57)$ & 0.43 \\
\hline
\end{tabular}

Values are reported as the number of eyes (\%) or median (interquartile range).

* Statistically significant at $p<0.05$.

and specificity for the diagnosis of craniopharyngioma. In our study, as in others, ${ }^{13,17}$ EOT was most often related to craniopharyngioma but not exclusively so.

The mechanism of EOT remains controversial. According to Nagahata et al., ${ }^{11}$ it may correspond to an inflammatory reaction of the brain tissue to the presence of the neoplasm (cytotoxic edema). Kawamura et al. ${ }^{8}$ asserted that it was caused by the leakage of serum from the newly formed blood vessels in a tumor lacking the normal bloodbrain barrier (vasogenic edema). Kearney et al. ${ }^{9}$ suggested that it could result from the leakage of the fluid content in the cystic areas of the tumor. In meningioma in adults, the roles of oligemia, altered metabolism surrounding the tumor, vascular endothelial growth factor, macrophages, and leukotrienes have been mentioned..$^{18}$ More recently, Saeki et al..$^{14,15}$ showed in 3 patients that EOT may be related to distended, large Virchow-Robin spaces. However, in our study, the dilation of the Virchow-Robin spaces was 
present in only 3 of the patients with edema, which does not support this hypothesis. Moreover, we observed this aspect in a child without edema.

The presence of EOT was not correlated with tumor size in our series as previously observed by others. ${ }^{6,11,15}$ This result may suggest the role of other factors, like the rate of tumor growth or a certain degree of histopathological aggressiveness, in both adults and children. This hypothesis is illustrated by the adult patients with pituitary metastasis: patients had visual impairment both when the tumor grew and when EOT appeared. ${ }^{13}$ In craniopharyngioma, despite its benign histology, the role of aggressive behavior rather than size in some of these tumors is supported by observations: the duration of clinical symptoms in the pediatric population is not related to visual impairment and tumor size?

The results of our study demonstrated that the visual field was significantly more damaged at diagnosis in the patients with edema when compared with the patients without edema: only 1 normal visual field was observed in the EOT group versus 6 in the group without edema. Interestingly, visual fields improved twice as much after treatment in the group with edema. Therefore, we suppose that EOT may result in significant impairment of vision and specifically alteration of the visual field, which could improve to a certain degree after treatment of the tumor. We also observed that the incidence of papilledema and optic disc pallor did not differ between the 2 groups. This result also argues against the role of tumor size and intracranial hypertension in the occurrence of edema. It also suggests the role of the local aggressiveness of the tumor toward neural tissue. The number of patients with papilledema in both groups was much lower than that in case series of other pediatric cerebral tumors and craniopharyngioma., ${ }^{1,410}$

Finally, and in accordance with these previous reports, the incidence of optic atrophy after treatment was higher than at diagnosis.

This study has some limitations. It is a retrospective study of nonstandardized ophthalmological examinations by multiple practitioners. The general condition of the children as a result of the tumors may have compromised the accuracy of the visual acuity and field measurements, and the study concerned a limited number of patients. However, this is the largest series reported so far, and the population is quite homogeneous because we excluded intrinsic tumors of the visual pathways. Furthermore, we suggest a global score of visual function that includes the visual acuity of both eyes, visual field results, and number of eyes impaired. This type of simple global score was previously proposed as a way to evaluate the ophthalmological history of pediatric patients with craniopharyngioma. ${ }^{4}$ It has the advantage of allowing easy comparison of pre- and postoperative examinations of each patient and between groups. Other data, like visual evoked potential, color and contrast vision, and retinal nerve fiber layer thickness as determined by optical coherence tomography, may also be used in the future to better understand this edema. However, complete standardized ophthalmological examination of children remains a challenge in the context of emergency.

Because we do not routinely use glucocorticosteroids in this type of situation, their potential beneficial influence on the evolution of EOT and visual function remains undefined. The role of surgery and its extent also represent an undetermined bias when evaluating the exact role of EOT on visual outcome in patients with these tumors, even in the context of a single-institution study and homogeneous surgical strategy.

\section{Conclusions}

Our study confirms that EOT in the context of a tumor of the sellar region in children is not necessarily associated with a less-favorable visual prognosis. It was not possible to distinguish specific factors that are responsible for the appearance of such edema because the cohort of patients was insufficiently small.

\section{Acknowledgments}

We thank Mrs. Deirdre McKeown for her help with writing the English-language version of this study.

\section{References}

1. Alswaina N, Elkhamary SM, Shammari MA, Khan AO: Ophthalmic features of outpatient children diagnosed with intracranial space-occupying lesions by ophthalmologists. Middle East Afr J Ophthalmol 22:327-330, 2015

2. Asaeda M, Kurosaki M, Kambe A, Takenobu A, Horie Y, Yamane Y, et al: [MR imaging study of edema along the optic tract in patient with Rathke's cleft cyst.] No To Shinkei 56:243-246, 2004 (Abstract) (Jpn)

3. Baggenstos M, Chew E, Butman JA, Oldfield EH, Lonser RR: Progressive peritumoral edema defining the optic fibers and resulting in reversible visual loss. J Neurosurg 109:313317,2008

4. Drimtzias E, Falzon K, Picton S, Jeeva I, Guy D, Nelson O, et al: The ophthalmic natural history of paediatric craniopharyngioma: a long-term review. J Neurooncol 120:651-656, 2014

5. Higashi S, Yamashita J, Fujisawa H, Yamamoto Y, Kadoya M: "Moustache" appearance in craniopharyngiomas: unique magnetic resonance imaging and computed tomographic findings of perifocal edema. Neurosurgery 27:993-996, 1990

6. Hirunpat S, Tanomkiat W, Sriprung H, Chetpaophan J: Optic tract edema: a highly specific magnetic resonance imaging finding for the diagnosis of craniopharyngiomas. Acta Radiol 46:419-423, 2005

7. Hoffmann A, Boekhoff S, Gebhardt U, Sterkenburg AS, Daubenbüchel AM, Eveslage M, et al: History before diagnosis in childhood craniopharyngioma: associations with initial presentation and long-term prognosis. Eur J Endocrinol 173:853-862, 2015

8. Kawamura A, Nagashima T, Fujita K, Tamaki N: Peritumoral brain edema associated with pediatric brain tumors: characteristics of peritumoral edema in developing brain. Acta Neurochir Suppl (Wien) 60:381-383, 1994

9. Kearney D, Tay-Kearney ML, Khangure MS: Craniopharyngioma and the moustache sign. Australas Radiol 37:370371, 1993

10. Lee HJ, Phi JH, Kim SK, Wang KC, Kim SJ: Papilledema in children with hydrocephalus: incidence and associated factors. J Neurosurg Pediatr 19:627-631, 2017

11. Nagahata M, Hosoya T, Kayama T, Yamaguchi K: Edema along the optic tract: a useful MR finding for the diagnosis of craniopharyngiomas. AJNR Am J Neuroradiol 19:17531757,1998

12. Pamir MN, Ozduman K, Belirgen M, Kilic T, Ozek MM: 
Outcome determinants of pterional surgery for tuberculum sellae meningiomas. Acta Neurochir (Wien) 147:1121-1130, 2005

13. Saeki N, Murai H, Kubota M, Fujimoto N: Oedema along the optic tracts due to pituitary metastasis. Br J Neurosurg 15:523-526, 2001

14. Saeki N, Nagai Y, Matsuura I, Uchino Y, Kubota M, Murai $\mathrm{H}$, et al: Histologic characteristics of normal perivascular spaces along the optic tract: new pathogenetic mechanism for edema in tumors in the pituitary region. AJNR Am J Neuroradiol 25:1218-1222, 2004

15. Saeki N, Uchino Y, Murai H, Kubota M, Isobe K, Uno T, et al: MR imaging study of edema-like change along the optic tract in patients with pituitary region tumors. AJNR Am J Neuroradiol 24:336-342, 2003

16. Shizukuishi T, Abe O, Haradome H, Fukushima T, Katayama Y, Sugitani M: Granular cell tumor of the neurohypophysis with optic tract edema. Jpn J Radiol 32:179-182, 2014

17. Siemons W, Wilms G, Theys T: Optic tract edema sign and craniopharyngiomas. JBR-BTR 93:28-29, 2010

18. Sklar EM, Schatz NJ, Glaser JS, Sternau L, Seffo F: Optic tract edema in a meningioma of the tuberculum sellae. AJNR Am J Neuroradiol 21:1661-1663, 2000

19. Stummer W: Mechanisms of tumor-related brain edema. Neurosurg Focus 22(5):E8, 2007

20. Takahashi M, Kinouchi H, Sasajima T, Suzuki A, Mizoi K: [A case of metastatic suprasellar tumor with edema along the optic pathway.] No Shinkei Geka 31:775-779, 2003 (Abstract) (Jpn)

21. Wang CW, Li YY, Zhu SG, Yang Y, Wang HW, Gong J, et al: Surgical management and evaluation of prognostic factors influencing postoperative visual outcome of suprasellar meningiomas. World Neurosurg 75:294-302, 2011

\section{Disclosures}

The authors report no conflict of interest concerning the materials or methods used in this study or the findings specified in this paper.

\section{Author Contributions}

Conception and design: Riffaud. Acquisition of data: Bussat, Proisy, Bruneau. Analysis and interpretation of data: Bussat, Proisy, Bruneau. Drafting the article: Bussat. Critically revising the article: Riffaud, Bussat, Proisy, Bruneau, Chappé. Reviewed submitted version of manuscript: Riffaud. Approved the final version of the manuscript on behalf of all authors: Riffaud. Statistical analysis: Bouzillé. Study supervision: Riffaud.

\section{Correspondence}

Laurent Riffaud: Pontchaillou University Hospital, Rennes, France.laurent.riffaud@chu-rennes.fr. 